\title{
Strengthening public health nutrition: findings from a situational assessment to inform system-wide capacity building in Ontario, Canada
}

\author{
Rachel JL Prowse ${ }^{1,2, *} \odot$, Sarah A Richmond ${ }^{1,3}$, Sarah Carsley ${ }^{1,3}$, Heather Manson 1,2,4 \\ and Brent Moloughney ${ }^{1,2}$ \\ 'Health Promotion, Chronic Disease and Injury Prevention, Public Health Ontario, Toronto, ON M5G 1V2, Canada: \\ ${ }^{2}$ Clinical Public Health Division, Dalla Lana School of Public Health, University of Toronto, Toronto, ON, Canada: \\ ${ }^{3}$ Epidemiology Division, Dalla Lana School of Public Health, University of Toronto Toronto, ON, Canada: ${ }^{4}$ School of \\ Public Health and Health Systems, University of Waterloo, Waterloo, ON, Canada
}

Submitted 11 0ctober 2019: Final revision received 16 March 2020: Accepted 14 April 2020: First published online 3 July 2020

\begin{abstract}
Objective: To assess public health nutrition practice within the public health system in Ontario, Canada to identify provincial-wide needs for scientific and technical support.

Design: A qualitative descriptive study was conducted to identify activities, strengths, challenges and opportunities in public health nutrition practice using semi-structured key informant interviews ( $n$ 21) and focus groups ( $n$ 10). Recorded notes were analysed concurrently with data generation using content analysis. System needs were prioritised through a survey.

Setting: Public health units.

Participants: Eighty-nine practitioners, managers, directors, medical officers of health, researchers and other stakeholders were purposively recruited through snowball and extreme case sampling.

Results: Five themes were generated: (i) current public health nutrition practice was broad, complex, in transition and collaborative; (ii) data/evidence/research relevant to public health needs were insufficiently available and accessible; (iii) the amount and specificity of guidance/leadership was perceived to be mismatched with strong evidence that diet is a risk factor for poor health; (iv) resources/capacity were varied but insufficient and (v) understanding of nutrition expertise in public health among colleagues, leadership and other organisations can be improved. Top ranked needs were increased understanding, visibility and prioritisation of healthy eating and food environments; improved access to data and evidence; improved collaboration and coordination; and increased alignment of activities and goals.

Conclusions: Collective capacity in the public health nutrition can be improved through strategic system-wide capacity-building interventions. Research is needed to explore how improvements in data, evidence and local contexts can bridge research and practice to effectively and efficiently improve population diets and health.
\end{abstract}

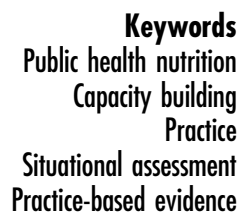

Poor diet and dietary inequities are public health and economic concerns in Canada ${ }^{(1)}$ and worldwide ${ }^{(2)}$. Diet-related diseases, such as cancer, heart disease and stroke, are leading causes of death globally ${ }^{(3)}$ and in Canada ${ }^{(4)}$. The longterm health consequences of a poor diet parallel the impacts of tobacco use as the leading cause of death and disability for adults, contributing $9.4 \%$ and $10.6 \%$ of total disability-adjusted life years in Canada, respectively ${ }^{(5)}$. In
2014, poor diets in Canada were estimated to contribute to $\$ 13.8$ billion (CAD) in direct and indirect health care costs $^{(1)}$. Canadians who lived in food insecure households, meaning they had insufficient food due to lack of money ${ }^{(6)}$, had poorer nutrient intakes ${ }^{(7)}$ and higher annual health care costs than those who lived in food secure households ${ }^{(8)}$.

Inadequate diets are common across the lifecourse. According to a Canadian national health survey, less than 
one-third of adolescents and adults consumed vegetables and fruits five or more times per day ${ }^{(9)}$, a validated indicator of dietary quality ${ }^{(10)}$. Approximately one-third of community dwelling older Canadians (65 years and older) are at nutritional risk $^{(11,12)}$. Canadian children (2-18 year olds) consumed significantly more total sugar daily now than a decade ago ${ }^{(13)}$. One study demonstrated that $25 \%$ of rural and urban preschoolers (18-35 months old) in Ontario, Canada were at high nutritional risk ${ }^{(14)}$.

Addressing unhealthy eating at a population level is complex due to the numerous and varied determinants of diet ${ }^{(15)}$. Physical, economic and social food environments in Canada often fail to comprehensively promote or support healthy eating when compared with international standards for healthy food environments ${ }^{(16)}$. A specialised field in public health, often referred to as public health nutrition, has emerged to promote healthy eating across populations ${ }^{(17)}$. Internationally, public health nutrition is understood to be the application of public health principles to engage in food- and nutrition-related health promotion and primary prevention of chronic disease through system-level, population-based educational, environmental and policy interventions $^{(17)}$.

Research around the world has focused on strategies to strengthen public health nutrition workforces ${ }^{(18-23)}$. Capacity building has been recognised as a cost-effective strategy to improve public health nutrition practice ${ }^{(18)}$ and can help improve implementation of evidence-based interventions, enhance public health leadership and align public health activities within and between organisations ${ }^{(24,25)}$. Building capacity in public health enables individuals, groups, organisations and systems to efficiently, effectively and sustainably carry out essential objectives ${ }^{(18)}$. In Ontario, Canada, public health units are mandated by the Ministry of Health to implement the Ontario Public Health Standards (OPHS) which identify the minimum expectations for public health programs and services to be delivered by Ontario's 35 boards of health'(26). The OPHS requires public health units to assess population health, address health equity, engage in effective evidence-based public health practice, and plan and manage public health emergencies $^{(26)}$. The OPHS includes brief recommendations to assess diets and food environments and promote healthy eating behaviours ${ }^{(26)}$.

Public Health Ontario, a crown corporation that provides scientific and technical support to public health units and the Ministry of Health, is well positioned to facilitate capacity-building interventions for the public health system. In response to a need to support public health practice in prioritised public health topics, one of which was healthy eating and food environments, Public Health Ontario created an Applied Public Health Science unit to lead innovative activities to build capacity across the public health system.

We undertook a situational assessment of public health nutrition practice within the Ontario public health system to identify needs for system-wide capacity-building activities. A situational assessment is an approach to inform planning by engaging stakeholders in assessing strengths, opportunities, needs and challenges of a situation ${ }^{(27)}$. The situational assessment aimed to: (i) understand the current state of public health nutrition within the Ontario public health system and (ii) identify system-wide priorities for scientific and technical support for public health nutrition practice.

\section{Methods}

\section{Study design and setting}

We used a qualitative descriptive method ${ }^{(28)}$ to conduct the situational assessment which included data generation by key informant interviews and focus groups, and a survey to prioritise needs identified from interviews and focus groups. This study was conducted in the province of Ontario, Canada which has a decentralised provincial public health system with 35 individual public health units serving an overall population of 14.4 million $^{(29)}$. Collectively, the Ministry of Health, Public Health Ontario and the public health units work to meet the public health needs of Ontarians. The Applied Public Health Science unit at Public Health Ontario is tasked with providing expert scientific and technical advice to support local public health units in implementing the OPHS and related evidence-based practices, programmes and policies in priority content areas, one of which is healthy eating and food environments. Thus, the situational assessment focused on understanding the state of public health nutrition practice from the perspective of public health units and relevant public health stakeholders.

\section{Sample and recruitment}

Participants (public health dietitians, managers, directors, medical officers of health, researchers and other relevant stakeholders) were purposively recruited through snowball sampling ${ }^{(30)}$ for key informant interviews. To start, we identified individuals who were known from previous involvement with healthy eating and food environment activities with Public Health Ontario. Participants were invited to participate in a key informant interview by email which included an information letter and the proposed interview questions. Participants were asked to schedule an interview if they were willing to participate. Participants were notified that their consent was implied by scheduling and participating in the interview; however, verbal consent was also obtained before the interview began. Additional potential participants were identified by interviewees and then invited by email by the lead author to participate until theoretical saturation was achieved when no new idea emerged during data collection and analysis ${ }^{(31)}$. We aimed for a range of participants 
at different levels (frontline to senior leadership) from a variety of public health units across the province to obtain a broad understanding of the public health system across Ontario.

Next, three public health units that differed in geography, size, structure and public health nutrition area focus (e.g., food systems, food insecurity) were selected by extreme case sampling. Extreme case sampling is a sampling strategy that identifies unusual cases with sufficient intensity of activities to assess factors that contribute to success or failure ${ }^{(19)}$. Extreme case sampling allowed us to identify diverse public health units highly engaged in public health nutrition activities and investigate features of those situations that can inform scientific and technical supports across the entire public health system. Selected public health units hosted in depth focus groups with practitioners, managers and senior leadership team members facilitated by the first author. Frontline practitioners (dietitians, other allied health professionals and staff who work on nutrition-related projects), managers, directors, medical officers of health and relevant other local stakeholders participated in focus groups at each public health unit. Focus groups were conducted separately by position-type (i.e., directors and medical officer of health in one group; frontline staff in another) as determined by the public health unit so as to encourage open participation. One contact person at each public health unit identified and invited participants to focus groups. Verbal agreement to participate was obtained before each focus group. Participants were reassured all focus groups were confidential and we asked all participants to respect the confidentiality of focus group discussions.

\section{Data collection and analysis}

Twenty-one key informant interviews and ten focus groups were conducted between July and December 2018. All but two key informant interviews were conducted over telephone. Focus groups were conducted in person (with the exception of one focus group where one participant telephoned into the focus group due to geographical constraints). The interviews and focus groups were semi-structured and asked questions on current activities, priority issues, strengths, challenges, opportunities for improvement and system-wide needs to support improved public health nutrition practice (see online Supplemental Files).

All interviews were audio-recorded after verbal consent was obtained by participants. Notes were made by the interviewer (R.P.), a trained qualitative researcher, during interviews supplemented with details from the audiorecording to ensure that responses were accurately captured $^{(32)}$. Transcripts were checked against recordings to ensure accuracy, adjusting if needed to correct errors. Focus groups were facilitated by the lead author (R.P.). Notes were made by R.P. during the focus groups supplemented by a second note taker when possible. Notes from interviews and focus groups were analysed by qualitative content analysis which is appropriate for qualitative descriptive studies where the aim is to remain close to the data in order to generate a 'straight descriptive summary of the informational contents of data organised in a way that best fits the data'(28, p. ${ }^{338)}$. NVivo 11 (QSR International, 2017) was used to organise data analysis.

\section{Rigor}

We used several verification strategies ${ }^{(33,34)}$ to facilitate investigator responsiveness to the data and increase internal validity and reliability including: concurrent data collection, analysis and sampling; purposive sampling for replication, saturation and thick descriptions in data; and peer review and debriefing. Member checking, which involves sharing data or analysis back to participants for feedback, may not be recommended as a verification strategy when data analyses aim to abstract and decontextualise the data at a higher level ${ }^{(33)}$; however, since our content analysis aimed to describe the situation and remain close to the data we decided it was appropriate for this study. Preliminary study findings were distributed to key informants and public health unit contacts as well as an additional twenty members of the field who had contacted the lead author to participate in the situational assessment after theoretical saturation had been achieved. A verification webinar was held in January 2019 where the preliminary findings were reviewed. Attendees were asked to discuss whether the findings reflected their perspectives and whether anything needed to be added or changed.

\section{Prioritisation}

System needs identified by participants during interviews and focus groups were summarised into nine high-level statements that crossed multiple themes. We created a survey to allow the field to prioritise the list of needs. The survey was distributed to key informant participants, public health unit site visit contacts and attendees of the verification webinar ( $n$ 64). Respondents were asked to rank a list of nine system needs from highest priority to lowest priority based on three criteria $^{(35)}$ :

1. Impact - the degree to which addressing this need would impact public health nutrition practice and healthy eating and food environments in Ontario.

2. Existing opportunities - whether a solution can build on existing efforts locally, provincially or nationally.

3. Feasibility - the certainty that a solution can be developed and implemented.

These criteria were selected because of their previous use in public health practice prioritisation exercises ${ }^{(35)}$, consistency with other situational assessments being conducted at Public Health Ontario ${ }^{(36,37)}$ and alignment with principles the public health field has historically used to 
prioritise activities ${ }^{(38)}$ thereby our participants would be familiar with.

Points were assigned per system need according to the rankings given by each respondent. When a system need was ranked as the highest priority, it was assigned nine points; the 2 nd highest was given eight points; the $3 \mathrm{rd}$ highest was given seven points and so on until the lowest priority system need was assigned one point. For each system need, the points were summed across all responses for a total score.

\section{Results}

\section{Participants}

Eighty-nine individuals participated in a key informant interview ( $n$ 52) or a focus group ( $n$ 37); five individuals participated in both. Frontline practitioners (e.g., dietitians) ( $n$ 47) and managers ( $n$ 25) made up the majority of the participants. Eight public health unit directors or medical officers of health participated. Nine participants were external to public health units (e.g., researchers, local and provincial partners). Ten interviews were conducted with a single participant but the remaining eleven interviews had multiple individuals interviewed simultaneously as they were part of an organised group related to public health nutrition practice (median $=2$ participants; range 2-17 participants). Focus groups were conducted with two to fourteen participants (median $=4$ ) depending on the size of the public health unit. Forty-one attendees, counted as the number of users logged onto the webinar, participated in the verification webinar. In some cases, attendees were logged in as a public health unit with multiple people in one room participating together; therefore, the actual participation is higher than this reported number of attendees.

\section{Themes}

We identified five themes in the data:

1. Current public health nutrition practice

2. Data, evidence and research

3. Guidance and leadership

4. Resources and capacity

5. Knowledge, attitudes and beliefs.

Each theme will be described in detail.

Theme 1: Current public bealth nutrition practice Participants described their current involvement in public health nutrition in Ontario by identifying defining characteristics and activities of their practice within their local region and across the province. Public health nutrition practice in Ontario was defined as:
- broad and complex due to the influence of multiple sectors and the social determinants of health related to diet, nutrition and food environments;

- collaborative and coordinated through a voluntary provincial non-governmental organisation (Ontario Dietitians in Public Health) within a decentralised public health system;

- $\quad$ in transition as evidenced by (i) an effort to shift towards upstream and environmental interventions and away from individual-focused, educational interventions, (ii) new guidance and leadership (e.g. new national dietary guidance and update public health standards) and (iii) reduced dedicated resources for public health nutrition;

- in competition with other public health topics for attention and resources, such as 'hot topics' (e.g., cannabis use) or risk factors with more proximal health outcomes.

Collaboration, coordination and advocacy were commonly mentioned facilitating factors for province-wide public health nutrition action, but participants also discussed local collaboration and coordination with community partners as well as advocacy (when appropriate) for local change to support healthy eating behaviours in their community. Nevertheless, some participants believed that a greater impact on population nutrition could be achieved with stronger collaboration, coordination and advocacy locally and provincially.

\section{Theme 2: Data, evidence and research}

Participants highlighted the importance of data, evidence, research and evaluation in their practice. Although data availability and accessibility was reportedly variable across the province (e.g., said to be generally better in larger public health regions), participants consistently identified gaps in data and evidence across many nutrition topics. Data on nutritional intake, dietary habits, food environments and food policies were reportedly lacking for Ontario and Canada. Detailed dietary data in Canada, collected occasionally through national health surveys (most recently in 2004 and 2015), have sample sizes that are insufficient for sub-provincial analyses. This leaves public health units without means to efficiently assess population nutrition and health in their regions, a requirement of the OPHS, unless they paid for additional surveys (e.g., Rapid Risk Factor Surveillance System) or participated in independent research with a local university. Furthermore, there was also a gap in methods (and/or knowledge of methods) to collect local data including a lack of indicators to measure the state of eating and food environments and/or the impact of interventions.

Practitioners also reported a gap in applicable evidence for (and/or knowledge of) effective public health nutrition practices and interventions. It was reported that there was limited evidence that could be used to guide the design and 
implementation of public health nutrition interventions. Participants attributed the insufficiency of evidence to the complexity of intervening on population- and system-level determinants of healthy eating. The decentralised nature of public health in Ontario was believed to contribute to duplicated analyses of provincial data and evidence syntheses for local situational assessments, associated with an inefficient use of resources. Collectively, inadequate local data and gaps in research and evaluation methods were seen to generate difficulties for participants to identify local needs, gain support for taking action, design recommended effective evidence-based interventions and evaluate impacts.

\section{Theme 3: Guidance and leadership}

Participants described that local and provincial public health nutrition practice was influenced by leadership in public health units, governments and other organisations that specify public health priorities and recommended actions. Many participants believed that the priority of nutrition in public health did not align with the strong evidence that poor diet is a risk factor for negative health outcomes. Priorities and recommended actions were often communicated through policy documents or reports, including municipal, provincial and federal nutritionrelated policy documents (e.g., municipal food strategies, the OPHS ${ }^{(26)}$ and Canada's Healthy Eating Strategy ${ }^{(39)}$ ). Other documents such as best practices, frameworks, grey literature, evidence reviews and reports were also cited often as guiding documents.

Participants expressed desire for aligned priorities and actions across the province citing that cross-sectoral collaboration may be needed to meaningfully impact the complex, upstream determinants of population diets. The lack of guidance and/or specificity in guidance documents, in particular the OPHS, was seen to enable multiple interpretations leading to different priorities and practices. The flexibility in the OPHS was seen as both a facilitator and barrier to advancing public health nutrition action as it allowed public health units to address local needs but may not encourage the broader momentum needed to act on determinants of diet that extend beyond local communities. Participants also identified that existing mandated provincial nutrition policies developed by different government ministries outside of health did not align with one another. Participants desired harmonised provincial food and nutrition strategies, goals and/or guidelines that were mandated and monitored to improve alignment and increase dedicated effort on public health nutrition topics.

Theme 4: Resources and capacity

Individual and organisational resources (human, financial) and capacity (knowledge, skills and time) to engage in public health nutrition practice were discussed by participants. Participants reported that resources and capacity varied by public health units, but stated there was always more work to be done than there were resources and capacity available even for public health units with the highest perceived level of capacity. Many public health units reported that resources dedicated to public health nutrition have reduced locally and provincially in recent years. Smaller public health units had less nutrition staff which required practitioners to have expertise across many public health nutrition topic areas (e.g., food insecurity, food systems, healthy growth and development, school nutrition, etc.). This was different than practitioners in larger public health units that commonly had narrower, specialised portfolios. Ontario Dietitians in Public Health, as a facilitator of collaboration and resource sharing, helped to compensate for low resources and capacity in some public health units; however, individual capacity to collaborate province wide was still reportedly insufficient due to the volunteer subscription nature of Ontario Dietitians in Public Health. Across all public health units, participants emphasised limited capacity to collect data, synthesise and critically appraise evidence, and conduct research or evaluation. Time and funding were the most commonly cited limitations, but some participants also felt that knowledge and skills to do the work were limited.

\section{Theme 5: Knowledge, attitudes and beliefs}

Participants discussed their perception of the knowledge, attitudes and beliefs held by colleagues, public health unit management and leadership teams, and government and non-governmental organisations with respect to public health nutrition as well as the role of public health dietitians. Participants felt that the severity of poor diets and their health consequences, and the impact of environmental factors on diet were inadequately understood and/or appreciated. In general, participants stated that health protection (e.g., food safety, infectious diseases) and educational approaches to healthy eating promotion were commonly emphasised in public health. Some participants also believed that there were misperceptions regarding the scope of practice of dietitians (i.e., beliefs that dietitians have a knowledge base restricted to food and nutrients with limited knowledge about broader determinants of healthy eating relating to food insecurity, food systems, food policy and food retail, to name a few). Some participants reported that roles and responsibilities of dietitians have been replaced by general health promotion specialists related to beliefs that the dietitians' scope of practice overlapped with other disciplines without nutrition expertise.

\section{Verification}

No new information relevant to the research aims was identified during the verification webinar. Attendees agreed with the high-level themes and restated many existing sub-theme components. Several emerging areas of focus were mentioned by attendees and were recommended 
to be added to the summarised findings (e.g., climate change, Indigenous health). Emerging and underrepresented topics within public health nutrition are critical to identify as system-wide knowledge gaps. However, the aim of this study was to understand the state of public health nutrition practice and the system in which it takes place. Since the themes identified are not specific to individual public health nutrition topics, we did not proceed to add a list of individual topics. In general, no major changes were made to the analyses or results following verification, but we asked survey respondents to identify the top public health nutrition topics relevant to each system need during the prioritisation exercise.

\section{Prioritisation}

The prioritisation survey was completed by nineteen participants representing an estimated response rate of $29 \%$; however, this maybe underestimated since it is possible that a single response represented multiple individuals from one public health unit. With nineteen survey responses, the highest total score a system need could receive was 171 points and the lowest total score a system need could receive was nineteen points. The ranked order of the system need statements is provided in Table 1 .

Respondents identified an average of thirteen different topic areas per system need that were perceived as priorities for action (range 10-17). The most frequently cited priority topic areas to be addressed were the food environment, food insecurity and the food system.

\section{Discussion}

This study highlighted several challenges in Ontario public health nutrition practice related to the complexity of the practice area, limited data and evidence, varied guidance and leadership mismatched with the state of evidence, limited resources and capacity, and misperceptions about the practice area and relevant expertise. Current public health nutrition practice was defined as broad and complex, in transition, but also collaborative and coordinated through a voluntary provincial non-governmental organisation (Ontario Dietitians in Public Health). Data and evidence on healthy eating and food environments were reportedly unavailable, inaccessible and/or not applicable to needs of local public health units. Participants had access to a variety of guiding documents which enabled local interpretation and action but underserved the field's need for specific intervention recommendations and broad support for change. Individual and organisational resources and capacity for public health nutrition were reportedly varied across public health units although were identified as insufficient for all. Participants perceived that there was room to improve the understanding of nutrition expertise and activities in public health held by others colleagues, public health unit leadership, governments and non-governmental organisations.

Although participants used the word 'capacity' to describe practitioners' and organisations' abilities to carry out activities, participants' descriptions of challenges and needs across themes collectively reflect Baillie and colleagues' broad conceptualisation of capacity building, where the performance of a system depends on factors at multiple levels ${ }^{(18)}$. Themes of data, evidence and research; guidance and leadership; and resources and capacity, parallel foundational components of capacity building identified by Baillie and colleagues including: intelligence (information to guide effective, systematic public health planning and problem-solving), leadership (levels of influence that impact the implementation of actions and strategies) and resourcing (funding, staff, infrastructure, knowledge and skills needed to generate action) $)^{(18)}$.

The top ranked potential solutions to the challenges identified by participants demonstrated a desire for system-wide solutions: increasing understanding, visibility and prioritisation of healthy eating and food environments in public health; improving access, availability and applicability of data and evidence related to healthy eating and food environments; further improving collaboration and coordination of public health nutrition action and increasing alignment of public health nutrition activities and goals.

Hughes argues that a competent public health nutrition workforce requires a system where multidisciplinary teams are collectively equipped with specialised nutrition expertise and knowledge and skills in: (i) research, surveillance and critical appraisal; (ii) social determinants of health, health promotion, public health sciences, public policy and advocacy; (iii) communication; (iv) management and leadership and (v) professional conduct, including knowing the roles of other public health professionals ${ }^{(21)}$. The themes and prioritised needs identified in this study can be mapped onto a capacity-building conceptual framework that aims to increase practitioners' collective capacity to implement evidence-based interventions (Fig. 1). Leeman et al. explain that practitioners' collective capacity can be enhanced by capacity-building support systems tailored according to the complexity of the topic (e.g., multisectoral and multidisciplinary topics that cross several socioecological levels), the uncertainty of the evidence (e.g., limited, weak or poorly generalisable evidence) and the local context ${ }^{(25)}$.

Figure 1 outlines how systems for evidence dissemination and capacity building in public health nutrition practice can be strengthened through addressing needs for improved access, availability and applicability of data and evidence related to healthy eating and food environments, and improving collaboration and coordination of public health nutrition action. The complexity and uncertainty of public health nutrition practice may be reduced 
Table 1 Ranked order of public health nutrition practice system needs

\begin{tabular}{|c|c|c|c|}
\hline Rank & Points ${ }^{*}$ & System need identified by participants & Most frequently mentioned priority topics \\
\hline 1 & 130 & $\begin{array}{l}\text { Public health action in healthy eating and food } \\
\text { environments is understood, visible and prioritised in } \\
\text { public health }\end{array}$ & $\begin{array}{l}\text { - Food environments (e.g., dietary, health and } \\
\text { economic impacts of environmental factors are } \\
\text { understood; need for upstream population-based } \\
\text { solutions) } \\
\text { - Food systems (e.g., the breadth of influences across } \\
\text { food systems that impact access to food and eating } \\
\text { behaviours are understood) }\end{array}$ \\
\hline 2 & 126 & $\begin{array}{l}\text { Improved access to (and knowledge of) high quality, } \\
\text { applicable evidence of effective practices and } \\
\text { interventions }\end{array}$ & $\begin{array}{l}\text { - Food environments (e.g., demographically and } \\
\text { regionally relevant effective interventions for } \\
\text { consumer and organisational settings) } \\
\text { - Food insecurity (e.g., municipal-level income-related } \\
\text { interventions; health equity) } \\
\text { - Food systems (e.g., evidence on effective strategies to } \\
\text { positively change the food supply; climate change) } \\
\text { - Food literacy (e.g., broader definition of food literacy } \\
\text { beyond 'food skills' and effective interventions with long- } \\
\text { term impacts) }\end{array}$ \\
\hline 3 & 114 & $\begin{array}{l}\text { Improved access to (and knowledge of) data and/or } \\
\text { data collection methods and tools (e.g., indicators) } \\
\text { that reflect the depth and type of work in public health }\end{array}$ & $\begin{array}{l}\text { - Diet (e.g., data on consumption and eating } \\
\text { behaviours; indicators for healthy eating) }\end{array}$ \\
\hline 4 & 113 & $\begin{array}{l}\text { Public health nutrition action is collaborative and } \\
\text { coordinated reducing duplicated efforts and } \\
\text { differences between regions (when desired) }\end{array}$ & $\begin{array}{l}\text { - Food systems (e.g., collectively assessing food } \\
\text { supply) } \\
\text { - Food environments (e.g., consistent definitions of } \\
\text { healthy food for multiple settings) } \\
\text { - Food insecurity (e.g., collaboration for provincial or } \\
\text { federal interventions) } \\
\text { - Food literacy (e.g., collaboration between local and } \\
\text { provincial partners) }\end{array}$ \\
\hline 5 & 105 & $\begin{array}{l}\text { Public health nutrition action is aligned as public health } \\
\text { units, stakeholders and partners work towards } \\
\text { identified common goals }\end{array}$ & $\begin{array}{l}\text { - Food insecurity (e.g., align actions and advocacy } \\
\text { between partners to generate systemic solutions) }\end{array}$ \\
\hline 6 & 85 & $\begin{array}{l}\text { Practitioners are equipped with the necessary } \\
\text { knowledge and skills to work on emerging public } \\
\text { health and nutrition topics }\end{array}$ & $\begin{array}{l}\text { - Food system (e.g., increased understanding of the } \\
\text { food system and capacity to influence food systems } \\
\text { with multiple disciplines) }\end{array}$ \\
\hline 7 & 80 & $\begin{array}{l}\text { Improved capacity to do research, critical appraisal, } \\
\text { evaluation, monitoring and surveillance }\end{array}$ & $\begin{array}{l}\text { - Food insecurity (e.g., support for monitoring of the } \\
\text { nutritious food basket) }\end{array}$ \\
\hline 8 & 58 & $\begin{array}{l}\text { Nutrition-related public health topics are integrated into } \\
\text { other topic areas where nutrition may not be the } \\
\text { primary focus }\end{array}$ & $\begin{array}{l}\text { - Food insecurity (e.g., integrate food insecurity into } \\
\text { social determinants of health) } \\
\text { - Mental health (e.g., integrate nutrition into mental } \\
\text { health) } \\
\text { - Food systems (e.g., integrate food systems into climate } \\
\text { change) }\end{array}$ \\
\hline 9 & 44 & $\begin{array}{l}\text { There is a multidisciplinary workforce prepared with the } \\
\text { skills and knowledge necessary to work on complex } \\
\text { upstream public health nutrition issues }\end{array}$ & $\begin{array}{l}\text { - Food environment (e.g., urban planners need to } \\
\text { understand community food environments; dietitians } \\
\text { need to understand urban planning) } \\
\text { - Food system (e.g., broad understanding of upstream } \\
\text { food supply interventions } v \text {. individual-focused } \\
\text { interventions) }\end{array}$ \\
\hline
\end{tabular}

*Out of a possible 171 points if the system need was ranked as most important by all survey respondents.

by addressing needs for data and evidence, and increasing understanding, visibility and prioritisation of healthy eating and food environments in public health. The practice context, which includes factors related to decisionmaking structure, capacity to innovate, stakeholder unity and fit of evidence with values and resources, may also be improved by addressing data and evidence needs; increasing understanding, visibility and prioritisation of public health nutrition practice and increasing alignment of public health nutrition activities and goals. These system-level interventions aim to improve the collective capacity of public health practitioners and the public health system.
Our findings re-emphasised the broad scope of public health practice in Canada that was identified by Fox et al. ${ }^{(40)}$. Although Fox et al. highlighted the need for improved collaboration and coordination in the Canadian public health nutrition field ${ }^{(40)}$, our results suggest that this may have improved over the last decade in Ontario. Internationally, public health nutrition fields in Australia ${ }^{(21,22)}$ and Europe $^{(20)}$ have similar functions and challenges. In Europe, public health nutrition professionals actively ${ }^{(20)}$ :

- research, monitor and assess diet, determinants of diet, programmes and policies,

- $\quad$ ensure healthy and safe environments, 


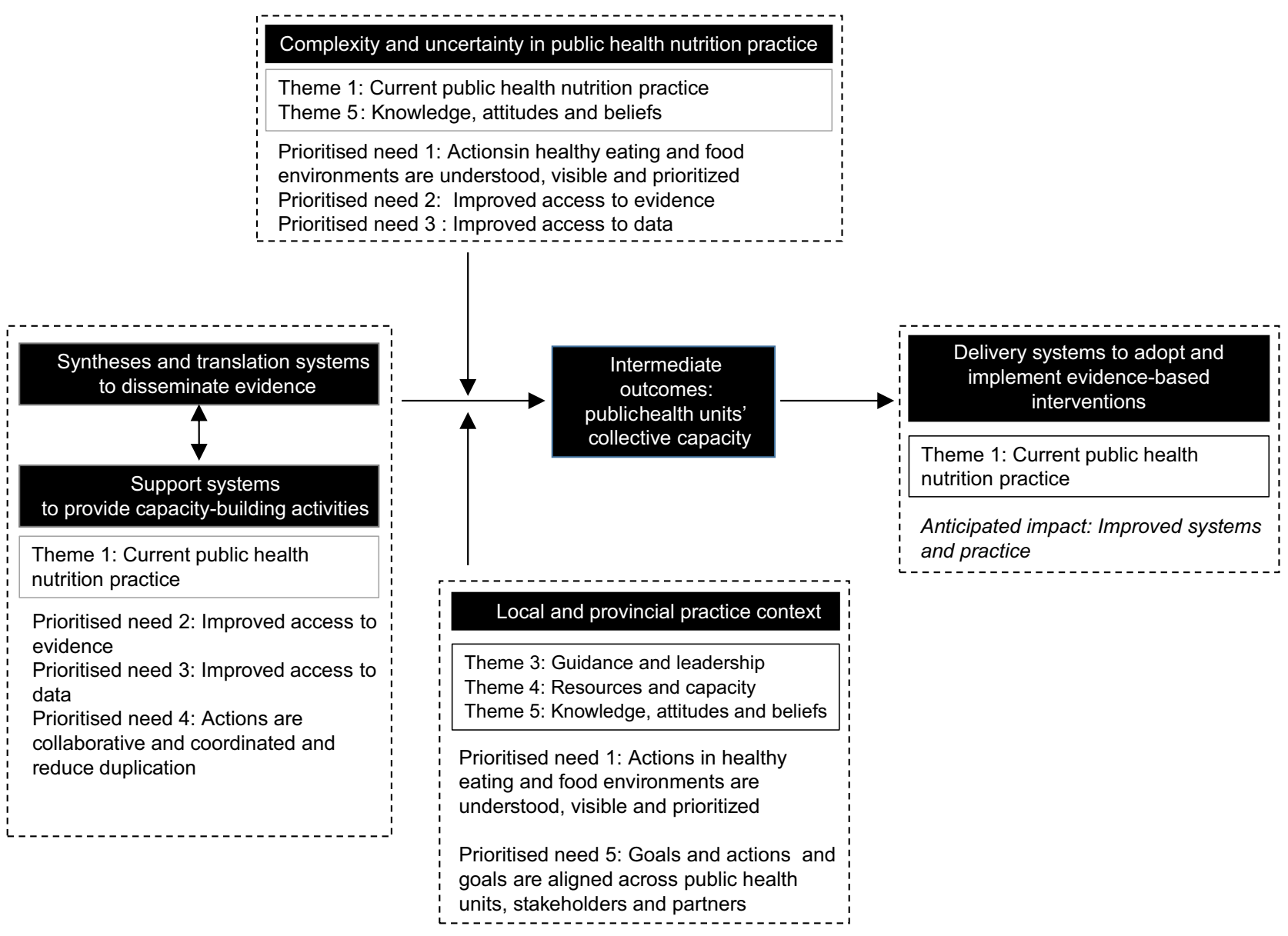

Fig. 1 Adapted capacity-building framework from Leeman et al. ${ }^{(25)}$ to address system-wide needs to advance public health nutrition practice

- $\quad$ provide population-level nutrition education and guidance,

- build community capacity,

- $\quad$ inform evidence-based policy and

- $\quad$ plan, implement and evaluate population nutrition interventions.

In Australia, the factors that influenced capacity and competency of the public health nutrition workforce align with the themes discussed by participants in the present study including infrastructure, dietary guidance, resource adequacy and collaboration ${ }^{(21,22)}$.

Situational assessments conducted on other Applied Public Health Science practice areas (injury prevention, and healthy growth and development) in Ontario revealed comparable challenges including gaps in data, evidence and research; limited resources and the need for improved collaboration $^{(36,37)}$. Furthermore, there are consistencies with the findings of the 2017 Ontario Auditor General's review of chronic disease prevention in public health including ${ }^{(41)}$ :

- the need for access to data, indicators and evidence specific to health promotion and chronic disease prevention that are aligned and shared across public health units;

- improved collaboration and coordination between public health units, with the provincial public health agency, as well as with the government health ministry and other relevant government ministries and

- high-level coordination or guidance through a chronic disease prevention strategy.

The consistencies across situational assessments in Ontario and research in public health nutrition worldwide suggest that the challenges experienced by the public health nutrition workforce may not be specific to the topic area but may be institutionalised, system-level factors that impact public health practice across multiple topic areas. Our adapted system-level capacity-building framework (Fig. 1) may be useful to inform capacity-building initiatives in other areas of public health practice in Ontario, as well as informing supports for public health nutrition practice worldwide. This framework will be used to guide plans for the Applied Public Health Science unit at Public Health Ontario to undertake system-wide capacity building to strengthen evidence-based public health nutrition 
practice in Ontario in the context of enhancing public health units' ability to implement the OPHS.

\section{Future research}

There are many implications for future research from this study, including understanding the state of population risk factors for poor diet, dietary intake across populations, effective and equitable interventions, and exploring new and emerging topics to public health nutrition. First, data and evidence on healthy eating and food environments are clearly needed in order to facilitate understanding and action of public health nutrition in Ontario. Although the evidence base for upstream food environments and policy interventions is growing in Canada ${ }^{(16,42,43)}$ and internationally ${ }^{(44-47)}$, practitioners on the ground remain somewhat uncertain of effective strategies to improve food environments and population diets. Resourced and supported dietary and food environment surveillance systems that enable local public health units to understand population diets and local communities may be a necessary antecedent to advancing the understanding, action and impact of public health nutrition in Ontario. Secondly, research is needed to break down the complexity of food environments, the interaction between the individual and the environment, and the real-life effectiveness of environmental and policy interventions (including multi-component and cross-sectoral interventions) on diets. Identifying equitable interventions to promoting healthy eating and food environments and/or approaches appropriate for priority populations, namely Indigenous people, are needed by the public health field to fulfill their required objectives. Thirdly, practitioners are asking for more research on emerging topics in public health nutrition. For example, the interaction between climate change and health is a multifaceted complex challenge facing public health; local public health units are looking for evidence to guide practice in this topic including how food systems and nutritional health are impacted.

Finally, research is needed on the design and function of public health systems around the world, including effective system-wide capacity-building interventions to support public health nutrition practice. Research should evaluate how to operationalise theoretical capacity-building frameworks to understand how improvements in foundational requirements for public health capacity (data, evidence, intelligence, resources, guidance, leadership and local contexts) can bridge research and practice to synergistically support practice-based evidence and evidence-based practice $^{(48)}$.

\section{Strengths and limitations}

This study is a novel project that investigated the public health system in Ontario with a focus on local practice related to healthy eating and food environments. The findings revealed many strengths and challenges across the province and highlighted several opportunities to improve public health nutrition research and practice. The prioritisation of system needs may be limited by self-selection bias as only a portion of invited individuals completed the survey. We were unable to transcribe interviews and focus groups verbatim due to resource constraints, which may have introduced data errors. However, the verification strategies used throughout the study promote strong internal validity and reliability of the results. The results of the study may be limited to the context of Ontario and may be biased towards factors relevant to local public health practitioners and the mandate of Public Health Ontario to provide scientific and technical support to the public health field. Nevertheless, findings on the complexity of public health nutrition and the data and evidence needed to implement effective population health interventions are unlikely to be a challenge unique to public health nutrition practitioners in Ontario.

\section{Conclusion}

Public health nutrition professionals in Ontario experience several challenges related to the complexity of the practice area; limited data and evidence; varied guidance and leadership; limited resources and capacity, and misperceptions about the practice area. Interventions to enhance the effectiveness of public health practice to improve healthy eating may require system-wide supports that address current practice challenges; increase access to data and evidence; improve usability and alignment of practical guidance; increase dedicated resources; and improve understanding and prioritisation of healthy eating and food environments in public health. As the largest province in Canada, improving the collective capacity of the Ontario public health system can have wide population health impacts. System-wide capacity building for public health nutrition in Ontario can help to improve the functioning of the system as a whole and its individual parts. Meaningful collaboration between public health nutrition practitioners, researchers, decisionmakers and other stakeholders, informed by the current state of practice, can help build collective capacity and in turn effectively and equitably improve population diets.

\section{Acknowledgements}

Acknowledgements: The authors would like to thank all of the participants in their contribution to this project. Financial support: None. Conflict of interest: None. Authorship: R.J.L.P., S.A.R., S.C., H.M. and B.M. informed the study design and methodological tools. R.J.L.P. conducted the study (recruitment, data collection, data analysis and manuscript writing). S.A.R. and S.C. supported data collection and analysis. All authors reviewed and approved 
the manuscript. Etbics of buman subject participation: This study was conducted according to the guidelines laid down in the Declaration of Helsinki and all procedures involving human subjects were approved by the Public Health Ontario Ethics Review Board. In the consent process, participants were informed that by scheduling and participating in the interview, their free and informed consent is implied. Verbal consent was obtained before the start of all interviews and focus groups.

\section{Supplementary material}

For supplementary material accompanying this paper visit https://doi.org/10.1017/S1368980020001433

\section{References}

1. Lieffers JRL, Ekwaru JP, Ohinmaa A et al. (2018) The economic burden of not meeting food recommendations in Canada: the cost of doing nothing. PLoS One 13, e0196333.

2. Candari CJ, Cylus J \& Nolte E (2017) Assessing The Economic Costs Of Unhealthy Diets And Low Physical Activity: An Evidence Review And Proposed Framework. Copenhagen, Denmark: WHO Regional Office for Europe.

3. World Health Organization (2018) The top 10 causes of death. https://www.who.int/news-room/fact-sheets/detail/ the-top-10-causes-of-death (accessed May 2019).

4. Statistics Canada (2017) The 10 leading causes of death, 2013. https://www150.statcan.gc.ca/n1/pub/82-625-x/2017001/ article/14776-eng.htm (accessed May 2019).

5. Alam S, Lang JJ, Drucker AM et al. (2019) Assessment of the burden of diseases and injuries attributable to risk factors in Canada from 1990 to 2016: an analysis of the Global Burden of Disease Study. CMAJ Open 7, E140-E148.

6. Gundersen C, Tarasuk V, Cheng J et al. (2018) Food insecurity status and mortality among adults in Ontario, Canada. PLoS One 13, e0202642.

7. Kirkpatrick SI \& Tarasuk V (2008) Food insecurity is associated with nutrient inadequacies among Canadian adults and adolescents. J Nutr 138, 604-612.

8. Tarasuk V, Cheng J, de Oliveira C et al. (2015) Association between household food insecurity and annual health care costs. CMAJ 187, E429-E436.

9. Statistics Canada (2017) Fruit and vegetable consumption, 2016. https://www150.statcan.gc.ca/n1/pub/82-625-x/2017001/ article/54860-eng.htm (accessed May 2019).

10. Garriguet D (2009) Diet quality in Canada. Health Reports 82003-XPE(2009003).

11. Morrison JM, Laur CV \& Keller HH (2019) SCREEN III: working towards a condensed screening tool to detect nutrition risk in community-dwelling older adults using CLSA data. Eur J Clin Nutr 73, 1260-1269.

12. Ramage-Morin PL \& Garriguet D (2013) Nutritional risk among older Canadians. Health Rep 24, 3-13.

13. Langlois K, Garriguet D, Gonzalez A et al. (2019) Change in total sugars consumption among Canadian children and adults. Health Reports 1209-1367, 10-19.

14. Simpson RJ, Gumbley J, Whyte K et al. (2015) Development, reliability, and validity testing of Toddler NutriSTEP: a nutrition risk screening questionnaire for children 18-35 months of age. Appl Physiol Nutr Metab 40, 877-886.

15. Prowse RJL \& Raine KD (2017) Population Determinants of Unhealthy Foods and Beverages. New York, NY, USA: Oxford University Press.
16. Vanderlee L, Goorang S, Karbasy K et al. (2017) Creating healthier food environments in Canada: Current policies and priority actions - Summary Report.

17. Hughes R (2003) Definitions for public health nutrition: a developing consensus. Public Health Nutr 6, 615-620.

18. Baillie E, Bjarnholt C, Gruber M et al. (2009) A capacitybuilding conceptual framework for public health nutrition practice. Public Health Nutr 12, 1031-1038.

19. Kugelberg S, Jonsdottir S, Faxelid E et al. (2012) Public health nutrition workforce development in seven European countries: constraining and enabling factors. Public Health Nutr 15, 1989-1998.

20. Jonsdottir S, Thorsdottir I, Kugelberg S et al. (2012) Core functions for the public health nutrition workforce in Europe: a consensus study. Public Health Nutr 15, 1999-2004.

21. Hughes R (2004) Competencies for effective public health nutrition practice: a developing consensus. Public Health Nutr 7, 683-691.

22. Hughes R (2003) Public health nutrition workforce composition, core functions, competencies and capacity: perspectives of advanced-level practitioners in Australia. Public Health Nutr 6, 607-613.

23. Swanepoel E, Fox A \& Hughes R (2015) Practitioner consensus on the determinants of capacity building practice in highincome countries. Public Health Nutr 18, 1898-1905.

24. Nores M \& Fernandez C (2018) Building capacity in health and education systems to deliver interventions that strengthen early child development. Ann NY Acad Sci 1419, 57-73.

25. Leeman J, Calancie L, Kegler MC et al. (2017) Developing theory to guide building practitioners' capacity to implement evidence-based interventions. Health Educ Behav 44, 59-69.

26. Ministry of Health and Long Term Care (2018) Ontario Public Health Standards: Requirements for programs, services, and accountability.

27. The Health Communications Unit at The Centre For Health Promotion (2001) Introduction to Health Promotion Planning Workbook, Version 3.0. Toronto, ON: University of Toronto.

28. Sandelowski M (2000) Whatever happened to qualitative description? Res Nurs Health 23, 334-340.

29. Statistics Canada (2019) Table 17-10-0009-01 Population estimates, quarterly.

30. Palinkas LA, Horwitz SM, Green CA et al. (2015) Purposeful sampling for qualitative data collection and analysis in mixed method implementation research. Adm Policy Ment Health 42, 533-544.

31. Mayan MJ (2009) Essentials of Qualitative Inquiry. Walnut Creek, CA: Left Coast Press.

32. Halcomb EJ \& Davidson PM (2006) Is verbatim transcription of interview data always necessary? Appl Nurs Res 19 , $38-42$.

33. Morse JM (2015) Critical analysis of strategies for determining rigor in qualitative inquiry. Qual Health Res 25, 1212-1222.

34. Morse JM, Barrett M \& Mayan M et al. (2002) Verification strategies for establishing reliability and validity in qualitative research. Int J Qual Methods 1, 13-22.

35. Chambers A, Richmond SA, Logan L et al. (2014) The development of a framework to integrate evidence into a national injury prevention strategy. J Public Health 37, 671-677.

36. Richmond S, Carsley S, Prowse R et al. (2020) How can we support best practice? A situational assessment of injury prevention practice in public health. BMC Public Health 20, 431.

37. Carsley S, Prowse R, Richmond S et al. (2020) Supporting public health practice in healthy growth and development in the Province of Ontario, Canada. Public Health Nurs $\mathbf{7}$, 412-421.

38. Ministry of Health and Long Term Care (2008) Ontario Public Health Standards 2008. Government of Ontario. 
39. Government of Canada (2019) Health Canada's healthy eating strategy. https://www.canada.ca/en/services/health/ campaigns/vision-healthy-canada/healthy-eating.html (accessed May 2019).

40. Fox A, Chenhall C, Traynor M et al. (2008) Public health nutrition practice in Canada: a situational assessment. Public Health Nutr 11, 773-781.

41. Office of the Auditor General of Ontario (2017) Annual Report 2017 Volume 1 of 2. Toronto, ON: Queen's Printer for Ontario, ISSN 1911-7070.

42. Olstad DL, Raine KD \& Nykiforuk CI (2014) Development of a report card on healthy food environments and nutrition for children in Canada. Prev Med 69, 287-295.

43. Vanderlee L \& L'Abbe MR (2017) Food for thought on food environments in Canada. Health Promot Chronic Disease Prev Canada: Res Policy Pract 37, 263.

44. Mahesh R, Vandevijvere S, Dominick C et al. (2018) Relative contributions of recommended food environment policies to improve population nutrition: results from a Delphi study with international food policy experts. Public Health Nutr 21, 2142-2148.
45. Phulkerd S, Vandevijvere S, Lawrence M et al. (2017) Level of implementation of best practice policies for creating healthy food environments: assessment by state and non-state actors in Thailand. Public Health Nutr 20, 381-390.

46. Swinburn B, Vandevijvere S, Kraak V et al. (2013) Monitoring and benchmarking government policies and actions to improve the healthiness of food environments: the government healthy food environment policy index. Obes Rev 14, 24-37.

47. Vandevijvere S \& Swinburn B (2014) International Network for Food and Obesity/non-communicable diseases (NCDs) Research, Monitoring and Action Support (INFORMAS). Towards global benchmarking of food environments and policies to reduce obesity and diet-related noncommunicable diseases: design and methods for nationwide surveys. BMJ Open 4, 005339.

48. Ogilvie D, Adams J, Bauman A et al. (2020) Using natural experimental studies to guide public health action: turning the evidence-based medicine paradigm on its head. J Epidemiol Community Health 74, 203-208. 